\title{
The transient atmospheric response to a reduction of sea-ice cover in the Barents and Kara seas
}

Article

Accepted Version

Ruggieri, P., Kucharski, F., Buizza, R. and Ambaum, M. H. P. (2017) The transient atmospheric response to a reduction of sea-ice cover in the Barents and Kara seas. Quarterly Journal of the Royal Meteorological Society, 143 (704). pp. 1632-1640. ISSN 1477-870X doi: https://doi.org/10.1002/qj.3034 (Part A) Available at https://centaur.reading.ac.uk/69816/

It is advisable to refer to the publisher's version if you intend to cite from the work. See Guidance on citing.

Published version at: http://dx.doi.org/10.1002/aj.3034

To link to this article DOI: http://dx.doi.org/10.1002/qj.3034

Publisher: Royal Meteorological Society

All outputs in CentAUR are protected by Intellectual Property Rights law, including copyright law. Copyright and IPR is retained by the creators or other copyright holders. Terms and conditions for use of this material are defined in the End User Agreement.

www.reading.ac.uk/centaur 
Central Archive at the University of Reading

Reading's research outputs online 


\title{
The transient atmospheric response to a reduction of sea-ice cover in the Barents and Kara seas
}

\author{
P. Ruggieri, ${ }^{\mathrm{a} *}$ F. Kucharski, ${ }^{\mathrm{b}}$ R. Buizza, ${ }^{\mathrm{c}}$ M.H.P. Ambaum ${ }^{\mathrm{d}}$ \\ ${ }^{a}$ Department of Physical and Chemical Sciences/CETEMPS, University of L'Aquila, Italy \\ ${ }^{\mathrm{b}}$ Earth System Physics Section, Abdus Salam International Centre for Theoretical Physics, Trieste, Italy and
} Center of Excellence for Climate Change Research/Department of Meteorology, King Abdulaziz University, Jeddah, Saudi Arabia

${ }^{\mathrm{d}}$ Department of Meteorology, University of Reading, UK

*Correspondence to: Paolo Ruggieri, Dept. of Physical and Chemical Sciences/CETEMPS, University of L'Aquila, via Vetoio, 67100 L'Aquila, Italy. E-mail: paolo.ruggieri@aquila.infn.it

The observed reduction of Arctic sea-ice has drawn a lot of interest for its potential impact on mid-latitude weather variability. One of the outstanding challenges is to achieve a deeper understanding of the dynamical processes involved in this mechanism. To progress in this area, we have designed and performed an experiment with an intermediate complexity atmospheric model. The experiment shows a transient atmospheric response to a surface diabatic heating in the Barents and Kara seas leading to an anomalous circulation first locally, then over the polar region and finally over the Euro-Atlantic sector. A hypothesis that explains the mechanisms for the propagation of the signal is put forward. The discussion of this hypothesis provides an insight into the nature of the link between sea-ice forcing and the modes of internal variability of the atmosphere. We demonstrate that after removal of sea ice in the Barents and Kara seas, first the linear atmospheric response dominates and is confined in the proximity of the heating area, then a large-scale response, associated also to eddy-feedback, is found and finally anomalies reach the lower-stratosphere and show a hemispheric pattern in the troposphere. These results identify the drivers of the tropospheric connection between sea-ice variability and the North Atlantic Oscillation and highlight the role of the lower stratosphere.

Key Words: $\quad$ Sea-ice reduction; troposphere-stratosphere coupling; North Atlantic Oscillation

This article has been accepted for publication and undergone full peer review but has not been through the copyediting, typesetting, pagination and proofreading process, which may lead to differences between this version and the Version of Record. Please cite this article as doi: $10.1002 / \mathrm{qj} .3034$

This article is protected by copyright. All rights reserved. 


\section{Introduction}

The impact of the variability of sea-ice cover in the Arctic is a topic widely debated in scientific literature. Some recent studies have outlined the complexity of the interaction between sea-ice and atmosphere (e.g. Vihma 2014; Cohen et al. 2014; Barnes 2013; Overland and Wang 2010).

One of the challenges raised by these studies is to understand the physical and dynamical processes that lead to the establishment of a physical link with mid-latitude weather. More specifically, one crucial aspect of this link is to quantify how forcings related to sea-ice variability interact with the internal variability of the atmosphere, for example the North Atlantic Oscillation (NAO). Specifically designed sensitivity experiments can help us understanding and quantifying this link.

Quantifying sources of complexity and mechanisms for the propagation of the signal from the Arctic to the midlatitudes is the focus of recent studies (Overland et al. 2015; Sellevold et al. 2016). A tropospheric connection between sea-ice and the NAO seen found by several studies (García-Serrano et al. 2015; Petoukhov and Semenov 2010; Wu and Zhang 2010; Honda et al. 2009; Deser et al. 2007; Alexander et al. 2004). In particular, Deser et al. (2007) performed an experiment aimed at analyzing the transient atmospheric response to Sea Surface Temperatures and Sea Ice anomalies in the North Atlantic. They showed how a st (within a few weeks) response to sea-ice changes in the North Atlantic and the Barents and Kara (B-K) seas projects onto the negative phase of the NAO and is driven by tropospheric eddy feedbacks. They encouraged researchers to perform additional experiments with different forcing patterns and atmospheric models to better understand the time scale and the amplitude of the response. Petoukhov and Semenov (2010) and Semenov and Latif (2015) found that different regimes of tropospheric response are associated with variations of sea-ice cover in the Barents and Kara (B-K) seas, and they find a strong non-linearity with respect to the amount of sea-ice removed. Nonetheless for a wide range of values of sea-ice cover, the response to sea-ice removal is mainly a negative phase of the Arctic Oscillation.

On theThiseartiond, is preteateids byigdoynd ghthaAldenights variability can also have a significant impact on the stratosphere, raising the question of how much of the previous link is explained by intrinsically tropospheric processes (see e.g. Kim et al. 2014; Peings and Magnusdottir 2014; Sun et al. 2015; Ruggieri et al. 2016).

García-Serrano et al. (2016) have demonstrated a variety of lagged teleconnections between sea-ice reduction and the NAO, and they find a preferred stratospheric pathway with a lag of 1 month.

The aim of this study is to analyse the transient atmospheric response to a reduction of sea-ice cover in the Barents and Kara seas in mid winter, using an intermediate complexity climate model. More specifically, we aim to understand how changes (with respect to climatology) in the B-K region affect the largescale circulation over the North Atlantic sector on an intraseasonal time scale.

In figure 1 we show features of the late-winter, atmospheric circulation associated with the recent decline of sea-ice cover in the B-K seas. Figure 1a shows the time series of monthly mean geopotential height (Z) anomalies in some key regions of the atmosphere. This kind of temporal evolution has been described also by Nakamura et al. (2015). The late winter atmospheric conditions indicate a near-surface warming of the Arctic polar cap, which is coincident with a warming in the polar stratosphere (see figure 1b). The anomaly in the troposphere over the North Atlantic is thus coincident with a signal in the lower-stratosphere. This feature has been identified also by Sellevold et al. (2016). The high-latitude warming is coincident with circulation anomalies in the midlatitudes. In figure 1c, we show the geopotential height anomaly at $300 \mathrm{hPa}(\mathrm{Z} 300)$ in February. The positive anomaly over B-K and over the North Atlantic is one of the major features associated with Arctic warming, and it has been found both in observations (Kim et al. 2014) and in model experiments (see e.g. Pedersen et al. 2016). The corresponding, low-level temperature pattern, which has been called Warm-Arctic Cold-Continents (WACC), is shown in figure $1 \mathrm{~d}$. The link between this pattern and many aspects of Arctic warming has been discussed by Cohen et al. (2014) and Overland et al. (2011). In this study we investigate how the local, dynamical response can propagate signal from the B-K region to the midlatitudes, in particular over
reserved. the North Atlantic sector. 
Understanding how the two regions are interlinked is key to be able to design models capable to reproduce the interaction, and hopefully exploit predictable signals linked to the B-K seaice cover variability, when trying to predict large-scale weather variability over the Euro-Atlantic sector. To achieve this, we have designed two sensitivity experiments that should help us explain the main features of figure 1. These experiments include two 100-member ensemble forecasts that have been analysed up to 60 days. In one of the two ensembles, sea-ice cover in the B-K seas is reduced. This highly idealised setup is used to understand the transient evolution of the atmospheric response to sea-ice reduction in the $\mathrm{B}-\mathrm{K}$ seas, with a focus on the mechanisms driving a)tropospheric response and a lower-stratospheric response.

After this Introduction, in section 2 we describe the methodology and the experimental setup used in this study. Then in section 3 we Show the results from these experiments, and we discuss the main mechanisms involved in the transient evolution shown in figure 1. Finally, in section 4 we discuss how the results of this study can help understand the winter mid-latitude response to sea-ice variability, focusing on the link with the circulation in the North Atlantic sector, and is section 5 we summarise our results.

\section{Methodology}

To investigate the questions raised in the Introduction, we use a simplified model, the Abdus Salam International Centre for Theoretical Physics, Atmospheric General Circulation Model (ICTP AGCM, version 41). The ICTP AGCM is an intermediate complexity atmospheric model, with eight vertical layers and a triangular truncation of horizontal spectral fields at total wave number 30 (T30L8; see documentation and verification web-page: http://users.ictp.it/ kucharsk/speedynet.html). It is a hydrostatic, $\sigma$-coordinate, spectral transform model in the vorticity-divergence form described by Bourke (1974), with semi-implicit treatment of gravity waves. The parametrised processes include short-wave and long-wave radiation, large-scale condensation, convection, surface fluxes of momentum, heat and moisture and vertical diffusion. Land and ice temperature anomalies are determined by a simple, one-layer thermodynamic model. A detailed description

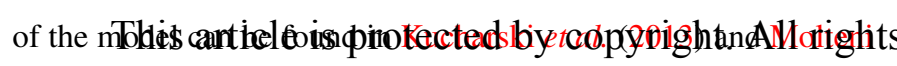
(2003).
The model has been used to investigate simple tropospherestratosphere interactions and a discussion around the suitability of the model is provided by Herceg-Bulic et al. (2017), thus showing that it is capable to capture some key features of the tropospherestratosphere interaction, despite the low top. The transient eddy heat and momentum fluxes climatology of the model is presented in figure S1 and S2 in the Supporting Information. A discussion on the suitability of the model to reproduce realistic transient eddy feedbacks can be found in Abid et al. (2015). Examples of the North Atlantic storm tracks response to surface forcings in the model can be found in Kucharski and Molteni (2003) and in Herceg-Bulić and Kucharski (2014).

To assess the transient evolution of the response we run an ensemble of 100 members starting from January $1^{s t}$, with initial conditions defined by a continuous, 100-year long run. In other words, the 100 initial conditions correspond to the first of January of each year in the continuous run. From this 100 initial conditions, we performed a reference (CTL) ensemble of integrations with climatological sea-ice cover and a perturbed (PRT) ensemble where sea-ice cover has been reduced to $10 \%$ of the climatological value over the area of the B-K seas (70N$80 \mathrm{~N}, 30 \mathrm{E}-75 \mathrm{E})$. The sea-ice reduction is maintained up to midFebruary. We also performed an experiment where the same sea-ice reduction is maintained only for the first two weeks of integration (PRT0). Since results of PRT0 are qualitatively in agreement with the first experiment, only results of PRT are presented in the main body of this article. Some results from PRT0 are discussed when they are relevant, and are reported in the Supporting Information (see figures S3,S4 and S5). A schematic of the experimental setup is shown in figure 2 , that shows the time series of the fraction of sea-ice removed in the PRT experiment (solid line) and the difference of surface temperature between the PRT and the CTL (black dots). The reduction of sea-ice induces an increase of the surface temperature (see figure 2) and a subsequent modification of the surface heat fluxes. Positive values of these heat fluxes cover the area where sea ice has been removed, while smaller negative values are found in the surroundings (see figure $\mathrm{S} 3 \mathrm{c}$ ), and this pattern has been found also by previous studies (see Ruggjeri et al. 2016; Sorokina et al. 2016). The net effect is a warming from the surface to the atmosphere, by both latent and 
sensible heat fluxes (not shown).

The temperature in the grid boxes that are partially covered by sea-ice is calculated as weighted average of the temperature over ice-free parts, $T_{\text {freeze }}=-1.8^{\circ} \mathrm{C}$, and the temperature over the icecovered-parts, $T_{\text {ice}}$, which is calculated from the slab ice model employing energy balance. Thus:

$$
T=c T_{\text {ice }}+(1-c) T_{\text {freeze }}
$$

where $c$ is the ice concentration of the grid cell. Since in winter he temperature over the parts covered by ice is typically far below freezing, the temperature perturbations induced by an ice removal are positive.

Data of geopotential height (Z) at 500 and $30 \mathrm{hPa}$, used in figure 1, are obtained form Era-Interim, the European Centre for MediumRange Weather Forecasts reanalysis (Dee et al. 2011). The field of $\mathrm{Z}$ is extracted six-hourly, on a $1^{\circ} \times 1^{\circ}$ longitude-latitude grid. Data of sea ice cover are obtained from the HadISST dataset (see Rhyner et al. 2003). Low ice years are selected as the 8 years with smaller sea ice cover in winter (DJF) in the area of the B-K seas $(70 N-80 N, 30 E-75 E)$.

\section{Results from the sensitivity experiments}

Figure 3 gives an overview of the tropospheric response averaged in February (i.e. the second month in the simulation). The zonal wind anomalies and the upper-level geopotential height pattern resemble the negative phase of the Northern Annular Mode (NAM), with an easterly anomaly over Scandinavia and Western Siberia. The temperature anomalies at $850 \mathrm{hPa}$ show a warming over the polar cap, mostly downstream, and a cooling over Siberia and North America. These features have been identified by authors who have studied the links between Arctic warming and midlatitude weather (see e.g. Outten and Esau 2012; Nakamura et al. 2015; Jaiser et al. 2016; Ruggieri et al. 2016). Anomalous zonal wind and $\mathrm{Z}$ projecting onto the pattern found in figure 3 are detectable up to day 60 , though varying significantly in magnitude (not shown).
3.3, we will present and discuss a hypothesis for the relevant physical processes involved.

\subsection{Regimes of tropospheric response}

From figure 4 and figure 5, which shows the zonal wind at 300 $\mathrm{hPa}$, and transient meridional heat fluxes at $850 \mathrm{hPa}$, we can see that:

- Days 1-20 (figures 4a,d and 5a) - During this first period, the signal is shallow, confined vertically in the lower troposphere and geographically in the heating area. The change in the local circulation is a cyclonic anomaly at 925 $\mathrm{hPa}$ and an anticyclonic anomaly at the higher levels (not shown). The zonal wind change is consistent with the $\mathrm{Z}$ field and the role of low-level transient eddies is confined in the region of anomalous heating.

- Days 21-40 (figures 4b,d and 5b) - During this second period, the low-level warming expands to cover the whole polar cap, with an intensification in the vicinity of the heating area (not shown). The $\mathrm{Z}$ at $300 \mathrm{hPa}$ shows an annular structure with one peak over the North Atlantic and one peak over B-K. The tropospheric warming in the polar region is still shallow, but a comparable increase of temperature is detected in the upper troposphere and the lower stratosphere. The change of the upper-level zonal wind is now large scale, it exhibits the signature of the negative phase of the NAO and it shows a dipolar anomaly in the longitudinal sector of B-K, which does not resemble the zonal wind adjustment to the local synoptic response found in the first 20 days. The wind anomalies are larger in the proximity of the heating area. Low level transient eddy heat fluxes are now stronger over the heating area, and interestingly they show a reduction of transient eddy activity in the region typically associated with the North Atlantic storm tracks.

- Days 41-60 (figures 4c,d and 5b) - The $300 \mathrm{hPa}$ zonal wind anomalies are mostly confined in the latitudinal band between $40 \mathrm{~N}$ and $60 \mathrm{~N}$, and over the North Atlantic. The transient heat fluxes at $850 \mathrm{hPa}$ are now nearly zero over

Hence, Fists iartictionis3plratectedrbye dopytnighthe Adhpigdits reserthedheating area; conversely, the negative heat fluxes are evolution of the atmospheric response. Then, in sections 3.2 and intensified over the North Atlantic. The signature of a 
negative NAO is now coincident with a slower zonal wind in the stratospheric polar cap.

Looking at the temporal evolution of the lower- and uppertroposphere response, two observations can be made: firstly, the initial, shallow and baroclinic response, which dominates for two weeks, is followed by a deep, barotropic response which is found both over the B-K seas and the North Atlantic. Secondly, this larger-scale response, which reaches the upper-troposphere, turns then into a hemispheric, NAM-like anomalous circulation.

he linear response of the atmosphere to a diabatic heating has been analysed by Hoskins and Karoly (1981). For a high-latitude, shallow, near-surface heating, the features of the linear response are a low at low levels, vorticity decreasing with height and a positive, shallow temperature anomaly over the heating. This response, that is dominant in the first 3 weeks of simulation, has een robustly linked with sea ice reduction by previous works (see e.g. Deser et al. 2007), and it is not further analysed in this study. The transition to a deep and large-scale response to sea-ice reduction is likely to be of uncertain interpretation, and its robustness is undermined by model-dependence (Barnes and Screen 2015). In the next section we focus on this deep response, then we provide arguments to explain how this response in the upper troposphere can modify the stratospheric circulation.

\section{Large-scale response mechanism}

Figure 4 showed that the most relevant changes in the zonally averaged circulation are detectable after 4-6 weeks, and these changes affect also the upper-troposphere and in the lower-stratosphere. Previous studies (see e.g. Nishii et al. 2011; Takaya and Nakamura 2008) suggested that an anticyclonic circulation over the B-K seas in late autumn and early winter affects the mid-winter stratospheric circulation, weakening the intensity of the westerly zonal wind. As documented by Deser et al. (2007), in mid-winter, the linear and non-linear response to sea-ice reduction interact destructively, resulting in a zero near-surface anomaly. They also show that, in their experiment, a negative NAO pattern is detected after 2-3 weeks. the B-K seas. These results show that a similar response can be obtained removing sea-ice only over the B-K seas, suggesting that a non-local mechanism propagates the signal upstream.

Ruggieri et al. (2016) discussed the changes of the uppertropospheric wave pattern associated to low sea ice and linked them with the intensity of the polar vortex one month ahead. The modification of the upper-tropospheric wavelike pattern is attributable to the barotropic stage of the local response over B-K. In fact, both the ridge over B-K and Scandinavia and the negative NAO would, in principle, lead to modifications of the zonally asymmetric circulation, resulting in a net positive meridional eddy heat flux. Considering these previous studies, the transition identified in the previous section can be described in terms of dynamical processes, namely: the transition from a direct and linear response, to an indirect and non-linear response (which is also non-local) and the subsequent modification of the upper-level wave pattern.

The reduction of the intensity of the transient heat fluxes in the Atlantic region (figure $5 \mathrm{~b}, \mathrm{c}$ ) coincides with the spreading of the warming from the heating area to the whole polar cap. The wavelike response to the heating triggers the zonal wind anomalies found after 20 days, when transient fluxes, which peak in the third stage, amplify the zonal wind anomaly.

Figure 6a shows the transient evolution of the meridional eddy heat flux at $100 \mathrm{hPa}$ and the integrated heat flux (defined as in Hinssen and Ambaum 2010). The heat flux is a measure of the upward propagation of planetary waves, and the integral shown in figure $6 \mathrm{a}$ is proportional to minus the potential vorticity anomaly at $30 \mathrm{hPa}$. In the first 3 weeks the signal is near zero, while at the end of January and up to the second week of February positive peaks are found. Then, in mid-February, a suppression of the heat flux persists for about two weeks. The integrated line (i.e. the dashed line in figure $6 a$ ) shows that the anomalous heat flux induces changes in the high-latitude, lower stratosphere that last for a couple of weeks and are particularly strong in mid-February. To understand how the anomalous tropospheric circulation induces changes in the upper-level heat flux, in figure

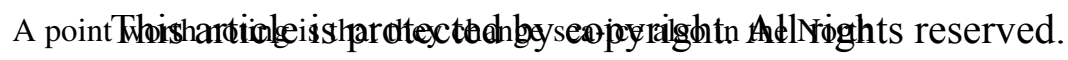

Atlantic sector (Labrador sea), while we reduce sea-ice only over 
$6 \mathrm{~b}$ we decompose the flux as following:

$$
\begin{aligned}
\left\{T_{p}^{*} v_{p}^{*}\right\}-\left\{T_{c}^{*} v_{c}^{*}\right\}= & \left\{T_{a}^{*} \bar{v}_{c}^{*}\right\}+\left\{\bar{T}_{c}^{*} v_{a}^{*}\right\}+ \\
& +\left\{T_{a}^{*} v_{a}^{*}\right\}+\left\{T_{a}^{*} v_{c}^{* \prime}\right\}+\left\{T_{c}^{* \prime} v_{a}^{*}\right\}
\end{aligned}
$$

where $p, c$ and $a$ indicate respectively the PRT run, the CTL run and their difference, the asterisk denotes a deviation from the zonal mean, the prime denotes a deviation from a temporal mean, quantities with overbars are temporally averaged and the parentheses denote a zonal and meridional average between $40^{\circ} \mathrm{N}$ $80^{\circ} \mathrm{N}$. In figure $6 \mathrm{~b}$, the red line shows how the first term in the RHS of equation 2 evolves in time. It indicates that a linear interaction of anomalous zonally asymmetric temperatures with the climatological zonally asymmetric circulation, is the main positive contribution to the heat flux. It persists from the Tast week of January to the end of February. The blue line in figure $6 \mathrm{~b}$ shows how the second term of the RHS of equation 2 evolves. Note that it gives a negative contribution after few weeks, when the nonlinear terms (dotted line) become relevant. Figure 7a shows anomalous and climatological fields of the 100 hPa zonally asymmetric temperature and $\mathrm{Z}$, averaged from day 10 to day 50. Figure 7 a suggests that the meridional transport of 1 warm air in the north Pacific and cool air over B-K explains the positive heat flux detected in figure $6 \mathrm{~b}$. Figure $7 \mathrm{~b}$ indicates that this late-winter pattern is also associated to sea-ice reduction in reanalysis, although smaller in magnitude in the model.

The NAM-like anomaly in February is the main feature of zonally averaged response, nonetheless, focusing on specific areas, other features have been identified. The peak of $\mathrm{Z}$ anomaly in the surroundings of the heating area occurs randomly, mostly between day 15 and day 50 (not shown). It is followed systematically by the NAO-like response with a lag of few days. With this in mind, the behaviour of the atmospheric response after the linear regime is likely to be flow dependent and, particularly over the North Atlantic sector, driven by a combination of dynamical processes. Thus, to further investigate this point, in figure $8 \mathrm{a}$ we show the regression of $\mathrm{Z}$ anomaly on the 100 $\mathrm{hPa}$ eddy heat flux anomaly. $\mathrm{Z}$ is averaged over the same areas

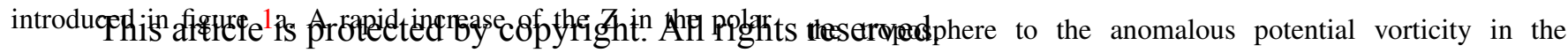
cap stratosphere is observed from lag -3 to lag 1 , then it slowly decreases over 3 weeks. A positive signal over the B-K area and over the North Atlantic in the upper-troposphere is found up to lag -4. Interestingly, the signal over the North Atlantic is found also at positive lags, after 2 weeks.

Both the first and the second peak of the $\mathrm{Z}$ anomaly over the North Atlantic are related to a shift of the jet and a reduction of transient eddy heat fluxes in the region upstream of the North Atlantic storm tracks (not shown). In the next section we discuss the differences between these two peaks focusing on the role of the lower stratosphere.

\subsection{The role of the lower stratosphere}

The tropospheric response to the forcing over the North Atlantic has two peaks, one is found along with the ridge over B-K, one is found after the hemispheric, upper-level response in the polar cap. Figure 8 also suggests that the two peaks of $Z$ response over the North Atlantic are associated to different spatial patterns and to different stages of the response. This finding is confirmed by figure $8 \mathrm{~b}, \mathrm{c}$, which shows the stereographic projection of the $\mathrm{Z}$ anomaly discussed in figure $8 \mathrm{a}$ at two selected lags, namely $-5 / 0$ and $+17 / 22$. The main feature detected in figure $8 \mathrm{~b}$ is the ridge over North Atlantic and Scandinavia, which is consistent with the intrinsically tropospheric response that has been associated to seaice reduction by previous studies (see e.g. Nakamura et al. 2015; Kug et al. 2015; King et al. 2016; Ruggieri et al. 2016). Figure 8c shows a rather different pattern, with a negative NAO signal. This result is found also in PRT0 (see figures S4 and S5), where the seaice forcing is nearly zero for positive lags. This finding indicates a delayed response. The hydrostatic and geostrophic adjustment of the Arctic troposphere to potential vorticity anomalies in the lower-stratosphere described by Ambaum and Hoskins (2002) provides a theoretical framework for the interpretation of these results. Figure 6 has shown how the response modifies the uppertropospheric wave pattern, leading to a net warm advection into the pole by means of the zonally asymmetric circulation. We have also demonstrated how this turns into a drop of the polar cap potential vorticity predicted by eddy heat flux. Following these considerations, it can be argued that an adjustment of stratospheric levels is a possible driver of the secondary peak 
found in figure 8a. The tropopause height anomaly in the polar cap (not shown) is indeed consistent with the above conjecture.

The low top of the atmosphere in the model and the simplicity of the stratospheric levels are a caveat for the implications that these results can have on the sea-ice NAO connection. Magnitude and time scales of the secondary peak found in figure 8 are likely to be significantly affected by detailed features of the model.

The combination of the patterns shown in figure $8 \mathrm{~b}, \mathrm{c}$ is displayed in figure 9. These panels are obtained taking an average in the two intervals defined in figure 8 and averaging them. Interestingly they can be compared with observed patterns presented in figure 1.

The last two and other crucial aspects of the experiment are discussed in the next section, where we give a summary of major results providing a unified view of the temporal evolution of the response and where we discuss how these results can be used to understand the role of sea-ice in seasonal predictability.

\section{Discussion}

The response of the atmosphere to temporally-confined sea-ice reduction in the Barents and Kara seas has been explained in terms of the transient response to enhanced surface turbulent heat fluxes associated to warmer surface temperatures. Two 100-member ensembles were run with different sea-ice cover during the first two weeks (PRT0) and during the first six weeks (PRT).

The forcing induces a warming of the polar cap (with maximum amplitude in the vicinity of the heating area), a southward shift of the low-level jet over the North Atlantic and Pacific oceans and a geopotential height anomaly that projects onto the negative phase of the NAM (figure 1). A detailed analysis suggested that the response can be decomposed into three distinct components: 1) a fast, linear and shallow response in the heating area

2) a deeper, indirect response associated to a wave-train over the heating area and a negative phase of the NAO

3) a slower response, with a negative NAO signal associated to a perturbation in the stratosphere.

Several studies (e.g. Kug et al. 2015; Grassi et al. 2013; Honda et al. 2009) suggested that, the intrinsically tropospheric

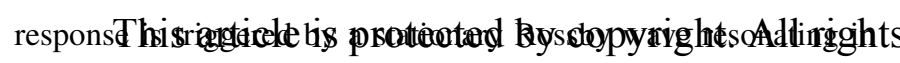
the surroundings of the heating area. Subsequently, the response is shaped by the internal variability of the atmosphere into the pattern of the negative phase of the NAO and transient fluxes have a major role in this stage (see figure $5 b$ ). As soon as the deep response establishes itself in the troposphere, a modification of the upper-tropospheric wave pattern produces an intensified eddy heat flux, which leads, after few days, to a drop of potential vorticity in the lower-stratosphere. The modified wave pattern consists of an intensified dipole of zonally asymmetric temperatures whose net effect is a stronger warm advection into the pole. This finding is consistent with the results of Takaya and Nakamura (2008). Sun et al. (2015) and Kim et al. (2014) also found the upper-level, intensified heat flux associated to sea-ice reduction in the Barents and Kara seas explained by modifications of a large wavenumber $\mathrm{Z}$ pattern in the upper-troposphere. Our analysis suggests that the modified zonally asymmetric temperature field has a central role, while the modified geopotential height field tends to reduce the heat flux.

Our experimental setup, allows to investigate the transient evolution of the response separating the component of the anomalous circulation in the troposphere linked directly to the sea ice forcing from a slower, atmospheric feedback. Results also show that a step function of sea-ice reduction is transmitted to the stratosphere resulting in a pulsed drop of potential vorticity in the polar cap. This impulse is found on average after about 6 weeks and is confined in a range of 15 days. At this stage, a negative NAO over the North Atlantic is detected, associated also to a stratospheric influence (figures $4,5,8$ ). Although the timing of this response is linked to the experimental setup and to model features, the associated dynamics appears robust.

The combination of the fast and slow response can explain the WACC pattern, which has been linked to a reduction of sea ice (see e.g Cohen et al. 2014; Overland et al. 2011). Figure 9 shows that the WACC near-surface temperature pattern can be obtained combining the two regimes of the response and that it is explained by the combination of the local circulation changes and a slower, large-scale adjustment linked with the perturbation in the stratosphere.

Several studies (e.g. Kim et al. 2014; Scaife et al. 2014; raiser etad: 2016) considered the seasonal cycle of the atmospheric response to a seasonal cycle of sea-ice anomalies. 
Recently, the attention of this class of studies has been drawn by a late winter response resembling the negative phase of the NAM which can be driven by the stratosphere. The present study suggests how to link the previously identified late winter circulation response to sea-ice perturbations. Sea ice reduction in other areas of the globe can have an opposite impact on the NAO (e.g. Kvamstø et al. 2004), a fact that raises the question to what factors control the dynamical link between a high-latitude, near surface heating and mid-latitude storm tracks. Realistic sea-ice anomalies persist throughout the winter season (see Kern et al. 2010), a fact that points out the need of a longer persistence of' sea-ice forcing in a model experiment. The magnitude of the anomalies induced by sea-ice forcing is small if compared with natural variability of the atmosphere, and also smaller than the correspondent pattern found in observation. Although, in our setup, neglecting autumn sea-ice can be a major cause of this discrepancy, the fact that model experiments tend to underestimate the response to sea-ice anomalies when compared to observations is not new, and it has been documented also in Scaife et al. (2014) and Kim et al. (2014). Moreover, a greater 7 agreement with observed patterns is found if the response is regressed and separated into two components, as shown in figures 8 and 9. These facts are supportive of a state-dependent interaction between the mid-latitude circulation and high latitude surface heat fluxes.

Results from this study highlight the separation between a direct and a delayed response, and between the tropospheric and the ratospheric component of the delayed response. One aspect that has been recently regarded as a challenge in modelling this polar-midlatitude interaction, is the disagreement found in the response of state-of-the-art models to Arctic warming (Barnes and Screen 2015). The interpretation of the response described in this study suggests that the mean position and the variability of the tropospheric jet, along with the interaction of climatological and anomalous planetary waves are potential key factors.

\section{Conclusion}

This study analysed the atmospheric response to sea ice reduction in mid-winter in the Barents and Kara seas in an intermediate complexity model. The model response shows the major, observed features of the atmospheric circulation associated to the recent sea-ice loss. The analysis of the associated dynamics gave insight into the mechanisms that can propagate the influence of sea-ice reduction to the mid-latitudes. Key features are the interaction of the local response with midlatitude jet and the modification of the upper-tropospheric wave pattern, that leads to a perturbation of the lower-stratosphere. More detailed investigations of the nature of the model response suggested that the contribution of sea-ice forcing to the observed patterns is likely to be state-dependent.

\section{Supporting Information}

The online version of this article contains supplementary material.

\section{Acknowledgements}

The first author would like to thank Guido Visconti of the University of L'Aquila and Jeff Knight and Douglas Smith of the UK Met Office, for helpful discussions.

\section{References}

Abid MA, Kang IS, Almazroui M, Kucharski F. 2015. Contribution of synoptic transients to the potential predictability of pna circulation anomalies: El niño versus la niña. Journal of Climate 28(21): 8347-8362.

Alexander MA, Bhatt US, Walsh JE, Timlin MS, Miller JS, Scott JD. 2004. The atmospheric response to realistic arctic sea ice anomalies in an agcm during winter. Journal of climate 17(5): 890-905.

Ambaum MHP, Hoskins BJ. 2002. The nao troposphere-stratosphere connection. Journal of Climate 15(14): 1969-1978, doi: 10.1175/1520-0442(2002)015 1969:TNTSC 2.0.CO;2, URL tp://dx.doi.org/10.1175/1520-0442(2002) 015<1969:TNTSC>2.0.CO;

Barnes EA. 2013. Revisiting the evidence linking arctic amplification to extreme weather in midlatitudes. Geophysical Research Letters 40(17): 4734-4739, doi:10.1002/grl.50880, URL http://dx.doi.org/10.1002/grl.50880.

Barnes EA, Screen JA. 2015. The impact of arctic warming on the midlatitude This article is protected by copyright. All rights reserstyedt: Can it? has it? will it? Wiley Interdisciplinary Reviews: Climate 
Bourke W. 1974. A multi-level spectral model. i. formulation and hemispheric integrations. Monthly Weather Review 102(10): 687701, doi:10.1175/1520-0493(1974)102〈0687:AMLSMI〉2.0.CO;2, URL http://dx.doi.org/10.1175/1520-0493 (1974) 102<0687:AM

Cohen J, Screen JA, Furtado JC, Barlow M, Whittleston D, Coumou D, Francis J, Dethloff K, Entekhabi D, Overland J, Jones J. 2014. Recent arctic amplification and extreme mid-latitude weather. Nature Geosci 7(9): 627637.

(1)

Dee DP, Uppala SM, Simmons AJ, Berrisford P, Poli P, Kobayashi S, Andrae U, Balmaseda MA, Balsamo G, Bauer P, Bechtold P, Beljaars ACM, van de Berg L, Bidlot J, Bormann N, Delsol C, Dragani R, Fuentes M, Geer AJ, Haimberger L, Healy SB, Hersbach H, Hólm EV, Isaksen L, Kållberg P, Köhler M, Matricardi M, McNally AP, MongeSanz BM, Morcrette JJ, Park BK, Peubey C, de Rosnay P, Tavolato C, Thépaut JN, Vitart F. 2011. The era-interim reanalysis: configuration and performance of the data assimilation system. Quarterly Journal of the Royal Meteorological Society 137(656): 553-597, doi:10.1002/qj.828, URL http://dx.doi.org/10.1002/qj.828.

Deser C, Tomas RA, Peng S. 2007. The transient atmospheric circulation response to north atlantic sst and sea ice anomalies. Journal of Climate 20(18): 4751-4767, doi:10.1175/JCLI4278.1, URL http://dx.doi.org/10.1175/JCLI4278.1.

García-Serrano J, Frankignoul C, King MP, Arribas A, Gao Y, Guemas V, Matei D, Msadek R, Park W, Sanchez-Gomez E. 2016. Multimodel assessment of linkages between eastern arctic sea-ice variability and the euro-atlantic atmospheric circulation in current climate. Climate Dynamics : 1-23doi:10.1007/s00382-016-3454-3, URL 1 http://dx.doi.org/10.1007/s00382-016-3454-3.

García-Serrano J, Frankignoul C, Gastineau G, de la Cámara A. 2015. On the predictability of the winter euro-atlantic climate: Lagged influence
of autumn arctic sea ice. Journal of Climate 28(13): 5195-5216, doi: 10.1175/JCLI-D-14-00472.1.

Grassi B, Redaelli G, Visconti G. 2013. Arctic sea ice reduction and extreme climate events over the mediterranean region. Journal of Climate 26(24): 10101-10 110, doi:10.1175/JCLI-D-12-00697.1, URL http://dx.doi.org/10.1175/JCLI-D-12-00697.1.

Herceg-Bulić I, Kucharski F. 2014. North atlantic ssts as a link between the wintertime nao and the following spring climate. Journal of Climate 27(1): 186-201, doi:10.1175/JCLI-D-12-00273.1, URL http://dx.doi.org/10.1175/JCLI-D-12-00273.1.

Herceg-Bulic I, Mezzina B, Kucharski F, Ruggieri P, King MP. 2017. Wintertime enso influence on late spring european climate: the stratospheric response and the role of north atlantic sst. International Journal of Climatology doi:10.1002/joc.4980.

Hinssen YBL, Ambaum MHP. 2010. Relation between the 100-hpa heat flux and stratospheric potential vorticity. Journal of the Atmos-

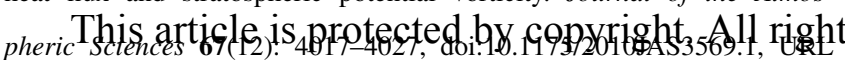

http://dx.doi.org/10.1175/2010JAS3569.1.

Honda M, Inoue J, Yamane S. 2009. Influence of low arctic seaice minima on anomalously cold eurasian winters. Geophysical SRéseârch. Lettêrs 36(8): n/a-n/a, doi:10.1029/2008GL037079, URL http://dx.doi.org/10.1029/2008GL037079. L08707.

Hoskins BJ, Karoly DJ. 1981. The steady linear response of a spherical atmosphere to thermal and orographic forcing. Journal of the Atmospheric Sciences 38(6): 1179-1196, doi: 10.1175/1520-0469(1981)038〈1179:TSLROA $\rangle 2.0 . C O ; 2$,

URL http://dx.doi.org/10.1175/1520-0469 (1981) 038<1179:TSLROA>2

Jaiser R, Nakamura T, Handorf D, Dethloff K, Ukita J, Yamazaki K. 2016. Atmospheric winter response to arctic sea ice changes in reanalysis data and model simulations. Journal of Geophysical Research: Atmospheres : n/a-n/adoi:10.1002/2015JD024679, URL http://dx.doi.org/10.1002/2015JD024679.2015JD024679.

Kern S, Kaleschke L, Spreen G. 2010. Climatology of the nordic (irminger, greenland, barents, kara and white/pechora) seas ice cover based on $85 \mathrm{ghz}$ satellite microwave radiometry: 1992-2008. Tellus A 62(4): 411-434, doi:10.1111/j.1600-0870.2010.00457.x, URL http://dx.doi.org/10.1111/j.1600-0870.2010.00457.x.

Kim BM, Son SW, Min SK, Jeong JH, Kim SJ, Zhang X, Shim T, Yoon JH. 2014. Weakening of the stratospheric polar vortex by arctic sea-ice loss. Nat Commun 5.

King MP, Hell M, Keenlyside N. 2016. Investigation of the atmospheric mechanisms related to the autumn sea ice and winter circulation link in the northern hemisphere. Climate Dynamics 46(3): 1185-1195, doi:10.1007/s00382-015-2639-5, URL http://dx.doi.org/10.1007/s00382-015-2639-5.

Kucharski F, Molteni F. 2003. On non-linearities in a forced north atlantic oscillation. Climate Dynamics 21(7): $\quad 677-687, \quad$ doi:10.1007/s00382-003-0347-z, URL http://dx.doi.org/10.1007/s00382-003-0347-z.

Kucharski F, Molteni F, King MP, Farneti R, Kang IS, Feudale L. 2013. On the need of intermediate complexity general circulation models: a speedy example. Bulletin of the American Meteorological Society 94(1): 25-30.

Kug JS, Jeong JH, Jang YS, Kim BM, Folland CK, Min SK, Son SW. 2015. Two distinct influences of arctic warming on cold winters over north america and east asia. Nature Geosci 8(10): 759-762.

Kvamstø NG, Skeie P, Stephenson DB. 2004. Impact of labrador sea-ice extent on the north atlantic oscillation. International Journal of Climatology 24(5): 603-612, doi:10.1002/joc.1015, URL http://dx.doi.org/10.1002/joc.1015.

Molteni F. 2003. Atmospheric simulations using a $\mathrm{gcm}$ with simplified physical parametrizations. i: model climatology and variability in multi-decadal experiments. Climate Dynamics 20(2): 175-191, doi:10.1007/s00382-002-0268-2, URL 
Nakamura T, Yamazaki K, Iwamoto K, Honda M, Miyoshi Y, Ogawa Y, Ukita J. 2015. A negative phase shift of the winter ao/nao due to the recent arctic sea-ice reduction in late autumn. Journal of Geophysical Research: Atmospheres 120(8): 3209-3227, doi:10.1002/2014JD022848, URL http://dx.doi.org/10.1002/2014 JD022848. 2014JD022848.

Nishii K, Nakamura H, Orsolini YJ. 2011. Geographical dependence observed in blocking high influence on the stratospheric variability through enhancement and suppression of upward planetary-wave propagation

Journal of Climate 24(24): 6408-6423, doi:10.1175/JCLI-D-10-05021.1, URL http: / / dx.doi.org/10.1175/JCLI-D-10-05021.1.

Outten S, Esau I. 2012. A link between arctic sea ice and recent cooling trends over eurasia. Climatic Change 110(3-4): 1069-1075.

Oyerland J, Francis JA, Hall R, Hanna E, Kim SJ, Vihma T. 2015. The melting arctic and midlatitude weather patterns: Are they connected? Journal of Climate 28(20): 7917-7932, doi:10.1175/JCLI-D-14-00822.1, URL http: / / dx.doi.org/10.1175/JCLI-D-14-00822.1.

Overland J, Wood K, Wang M. 2011. Warm arctic - cold continents: climate impacts of the newly open arctic sea. Polar Research 30(0), URL

http://www.polarresearch. net/index.php/polar/articl

Oyerland JE, Wang M. 2010. Large-scale atmospheric circulation changes are associated with the recent loss of arctic sea ice. Tellus A 62(1): 1-9.

Pedersen RA, Cvijanovic I, Langen PL, Vinther BM. 2016. The impact of regional arctic sea ice loss on atmospheric circulation and the nao. Journal of Climate 29(2): 889-902, doi:10.1175/JCLI-D-15-0315.1, URL (nttp://dx.doi.org/10.1175/JCLI-D-15-0315.1.

Peings Y, Magnusdottir G. 2014. Response of the wintertime northern hemisphere atmospheric circulation to current and projected arctic sea ice decline: A numerical study with cam5. Journal of Climate 27(1): 244-264, doi:10.1175/JCLI-D-13-00272.1, URL http://dx.doi.org/10.1175/JCLI-D-13-00272.1.

Petoukhov V, Semenov VA. 2010. A link between reduced barents-kara sea ice and cold winter extremes over northern continents. Journal of Geophysical Research: Atmospheres 115(D21): n/a-n/a, doi:10.1029/2009JD013568, URL http: //dx.doi.org/10.1029/2009JD013568. D21111. Rayner N, Parker DE, Horton E, Folland C, Alexander L, Rowell D, Kent E, Kaplan A. 2003. Global analyses of sea surface temperature, sea ice, and night marine air temperature since the late nineteenth century. Journal of Geophysical Research: Atmospheres 108(D14).

Ruggieri P, Buizza R, Visconti G. 2016. On the link between barents-kara sea ice variability and european blocking. Journal of Geophysical Research: Atmospheres 121(10): 5664-5679, doi:10.1002/2015JD024021, URL http://dx.doi.org/10.1002/2015JD024021. 2015JD024021.

Scaife AA, Arribas A, Blockley E, Brookshaw A, Clark RT, Dunstone N, Eade R, Fereday D, Folland CK, Gordon M, Hermanson L, Knight JR, Lea DJ, MacLachlan C, Maidens A, Martin M, Peterson AK, Smith D, Vellinga M, Wallace E, Waters J, Williams A. 2014. Skillful longThis article is protected by copyright. All rights reserved.
Research Letters 41(7): 2514-2519, doi:10.1002/2014GL059637, URL http://dx.doi.org/10.1002/2014GL059637.2014GL059637.

Sellevold R, Sobolowski S, Li C. 2016. Investigating possible arcticmidlatitude teleconnections in a linear framework. Journal of Climate 29(20): 7329-7343.

Semenov VA, Latif M. 2015. Nonlinear winter atmospheric circulation response to arctic sea ice concentration anomalies for different periods during 1966-2012. Environmental Research Letters 10(5): 054020.

Sorokina SA, Li C, Wettstein JJ, Kvamstø NG. 2016. Observed atmospheric coupling between barents sea ice and the warm-arctic cold-siberian anomaly pattern. Journal of Climate 29(2): 495-511, doi:10.1175/JCLI-D-15-0046.1, URL http://dx.doi.org/10.1175/JCLI-D-15-0046.1.

Sun L, Deser C, Tomas RA. 2015. Mechanisms of stratospheric and tropospheric circulation response to projected arctic sea ice loss. Journal of Climate 28(19): 7824-7845, doi:10.1175/JCLI-D-15-0169.1, URL http://dx.doi.org/10.1175/JCLI-D-15-0169.1.

Takaya K, Nakamura H. 2008. Precursory changes in planetary wave activity $/ v$ formidwinter surface pressure anomalies over the arctic. Journal of the Meteorological Society of Japan. Ser. II 86(3): 415-427, doi:10.2151/jmsj. 86.415 .

Vihma T. 2014. Effects of arctic sea ice decline on weather and climate: A review. Surveys in Geophysics 35(5): 1175-1214, doi:10.1007/s10712-014-9284-0, URL http://dx.doi.org/10.1007/s10712-014-9284-0.

Wu Q, Zhang X. 2010. Observed forcing-feedback processes between northern hemisphere atmospheric circulation and arctic sea ice coverage. Journal of Geophysical Research: Atmospheres 115(D14): n/a-n/a, doi:10.1029/2009JD013574, URL http://dx.doi.org/10.1029/2009JD013574. D14119. 
a) $Z 300$ and $Z 30$ anomaly

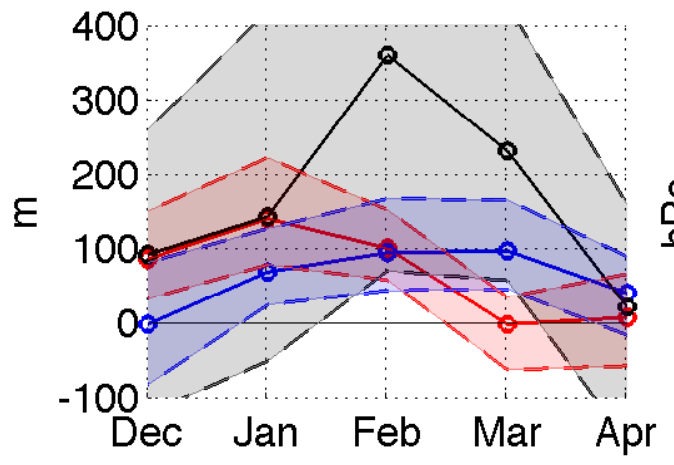

c) FEB $Z 300(\mathrm{~m})$ anomaly

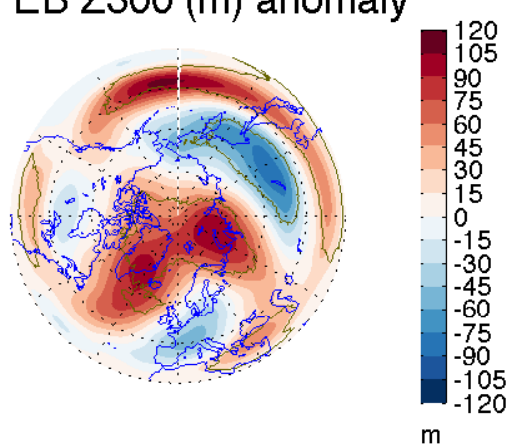

b) FEB $T$ and $u$ anomaly

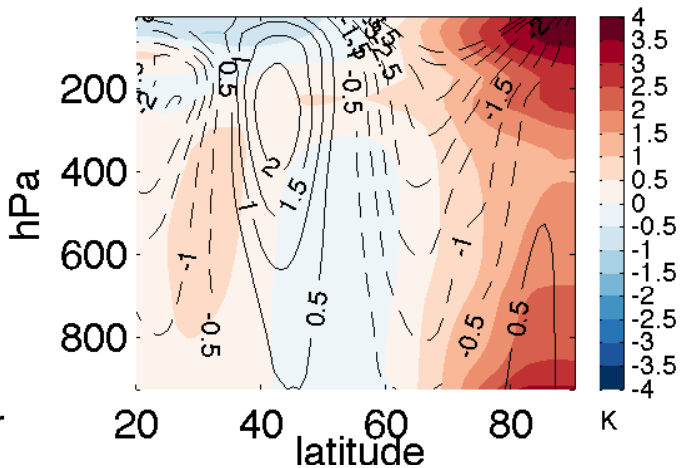

d) FEB T850 (K) anomaly

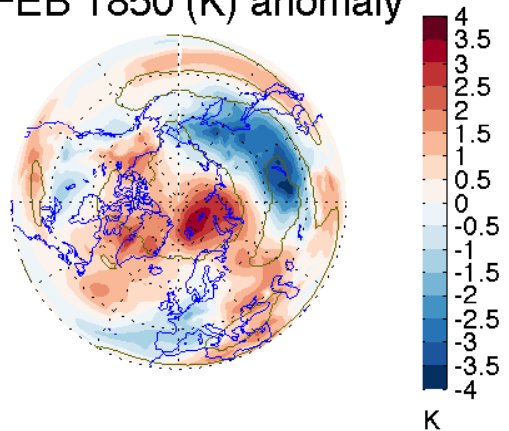

This article is protected by copyright. All rights reserved. 


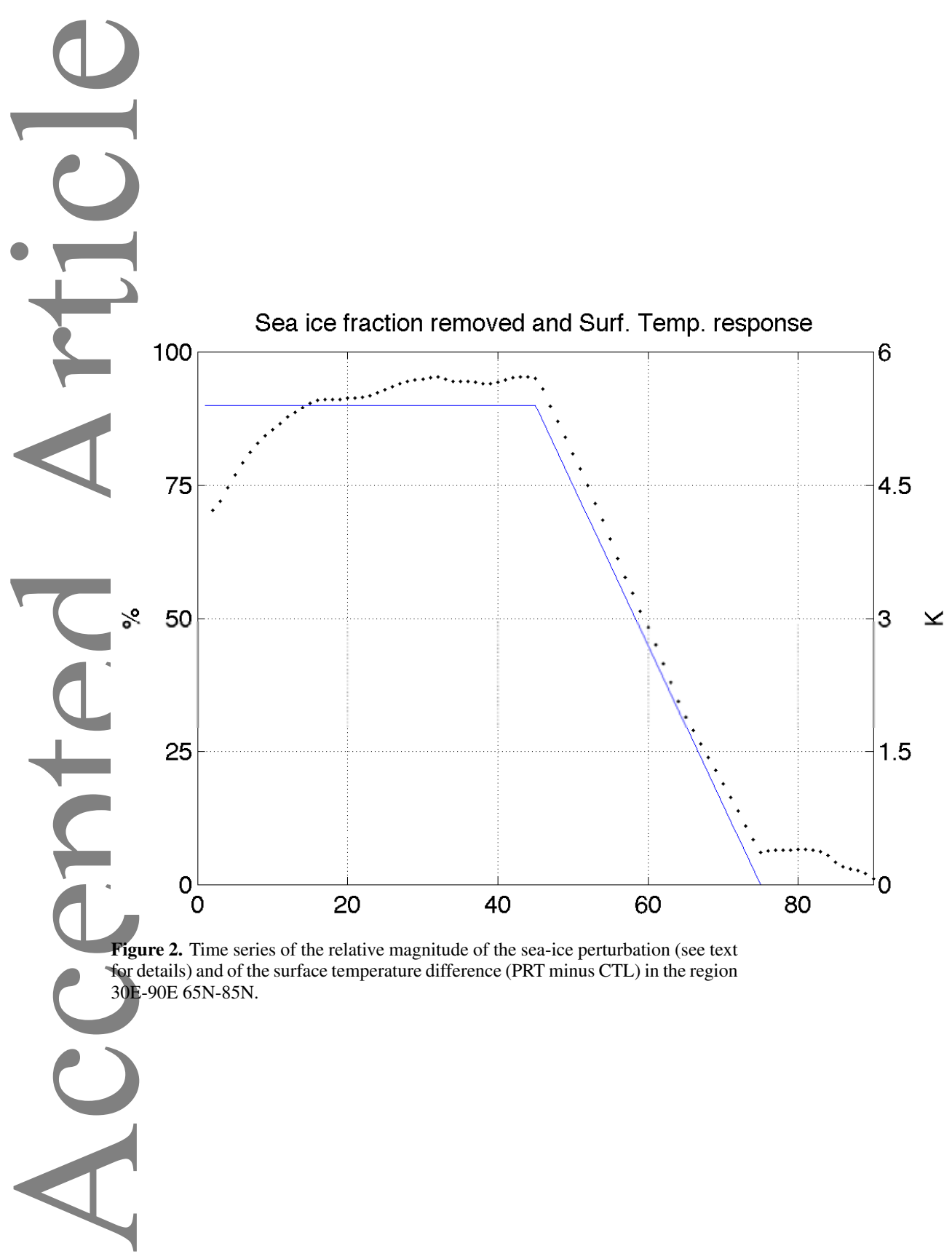

This article is protected by copyright. All rights reserved. 
a) $Z 300(\mathrm{~m})$ and $U 300(\mathrm{~m} / \mathrm{s})$, FEB, PRT-CTL

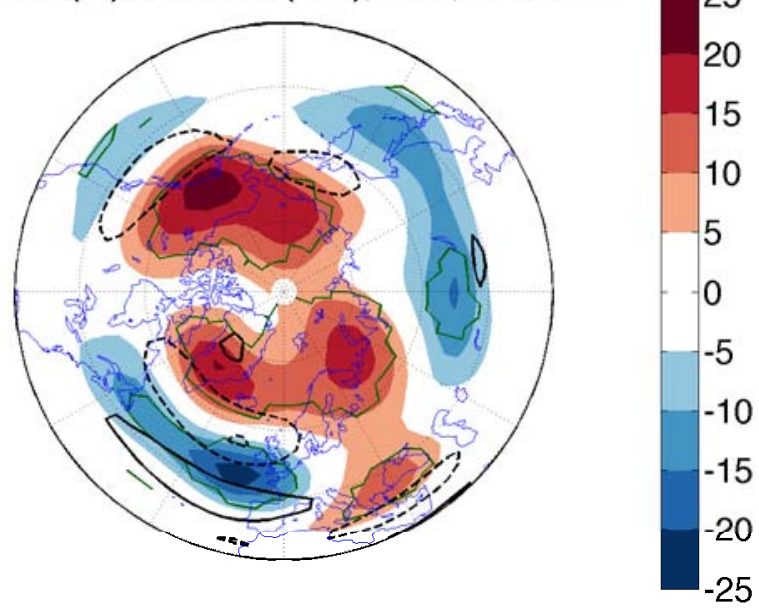

b) $T 850(\mathrm{~K})$ and $\mathrm{U} 850(\mathrm{~m} / \mathrm{s})$, FEB, PRT-CTL

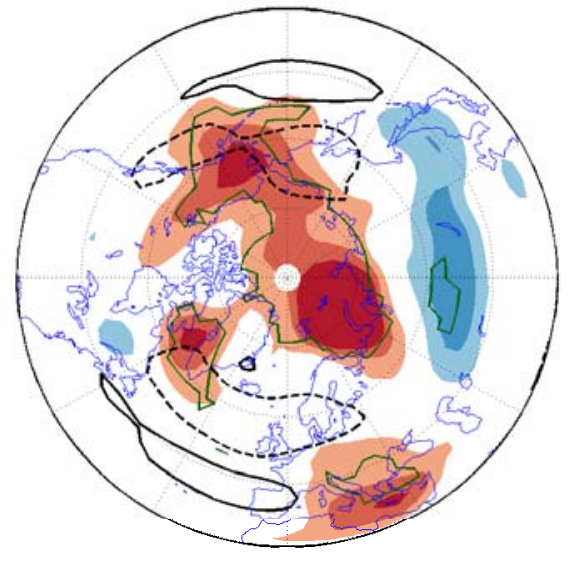

Figure 3. a) Geopotential height (shading, $\mathrm{m}$ ) and zonal wind (contours, drawn every $1 \mathrm{~m} / \mathrm{s}$ ) at $300 \mathrm{hPa}$ difference (PRT-CTL) for days 31-60 of simulation (i.e.

February). b) As in a) but for temperature (shading, K) and zonal wind (contours, drawn every $0.5 \mathrm{~m} / \mathrm{s}$ ) at $850 \mathrm{hPa}$. The green solid line encompasses statistically significant values at $99 \%$ confidence level according to a ranksum Wilcoxon test.

This article is protected by copyright. All rights reserved. 
a) U and T PRT-CTL Days 1-20

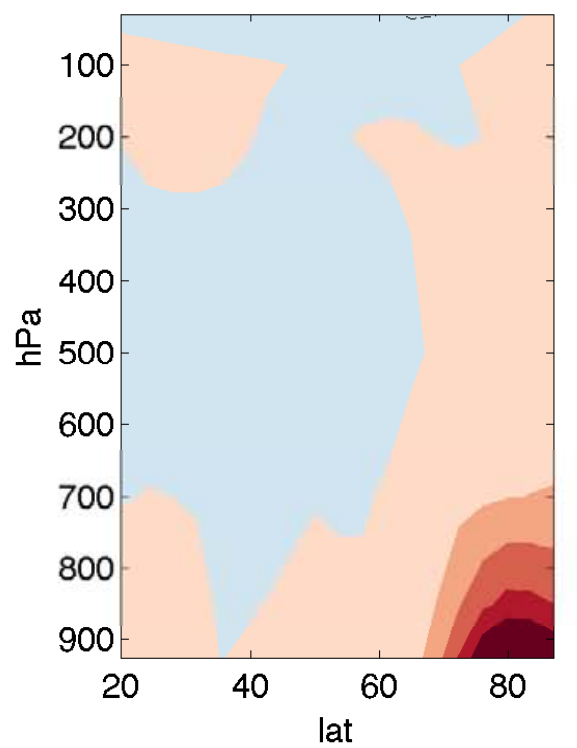

PRT-CTL T and U

b) $U$ and TPRT-CTL Days 21-40

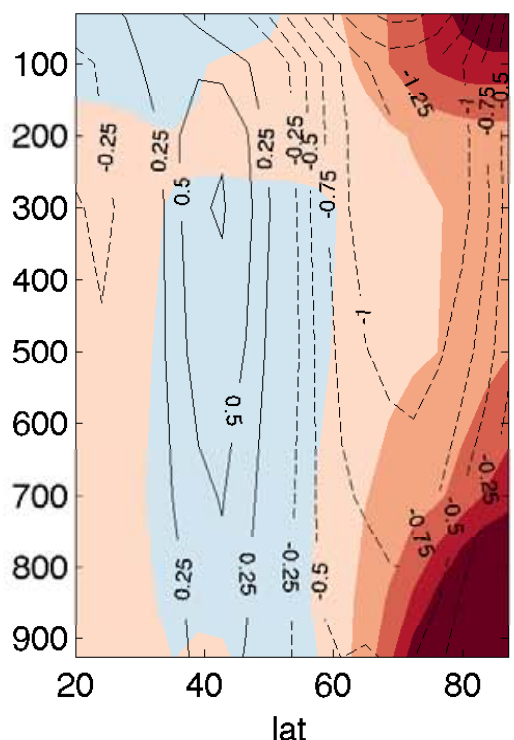

d) PRT-CTL Z30 and Z300 c) U and T PRT-CTL Days 41-60

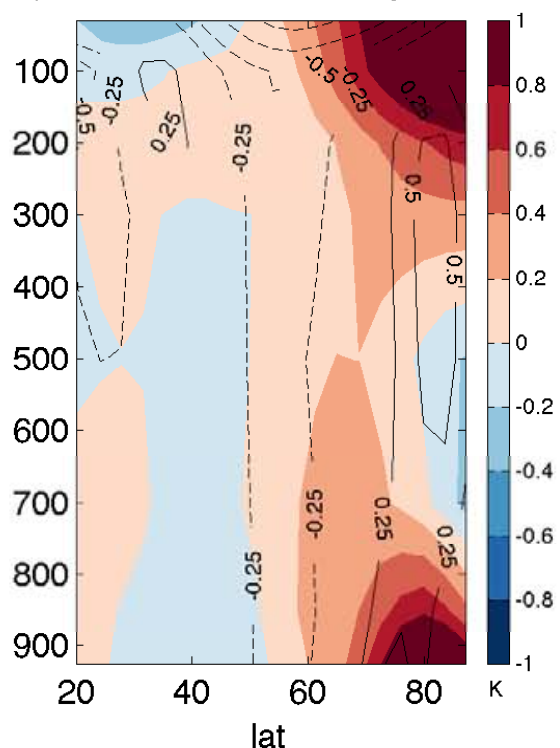

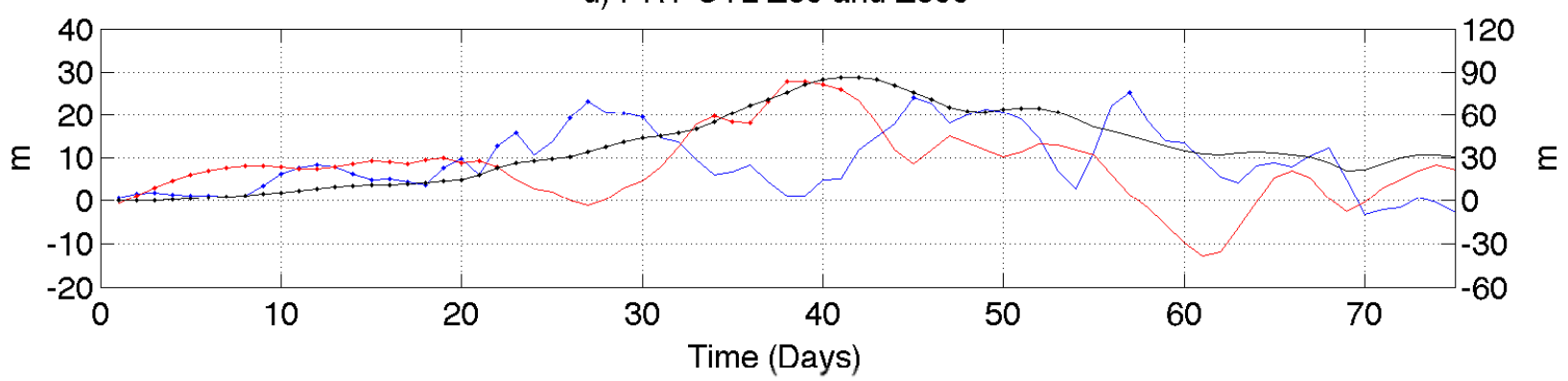

Figure 4. Latitude-pressure cross sections for $\mathrm{U}$ (contours, $\mathrm{m} / \mathrm{s}$ ) and $\mathrm{T}$ (colors, $\mathrm{K}$ )

anomaly for days a) 1-20, b) 21-40, c) 41-60. d) Time series of Z300 over the North Atlantic (blue line) and B-K seas (red line) and Z30 over the Arctic polar cap (black line). Dots indicate statistical significance at $95 \%$ confidence level according to a signed-rank Wilcoxon test.

This article is protected by copyright. All rights reserved. 
a) PRT-CTL U300 and v'T', days $1-20$

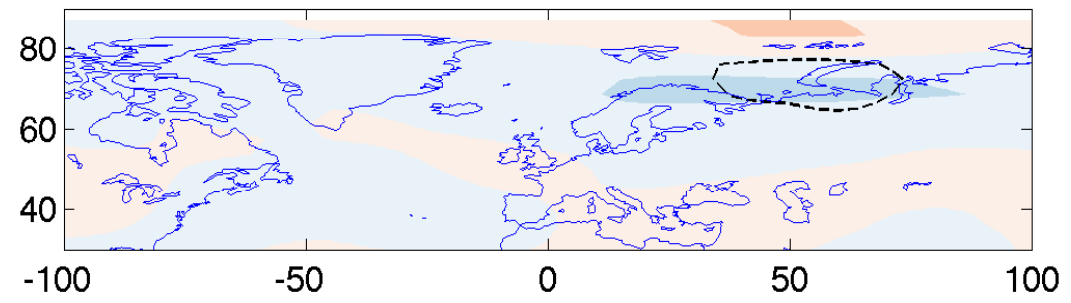

b) PRT-CTL U300 and v'T', days 21-40

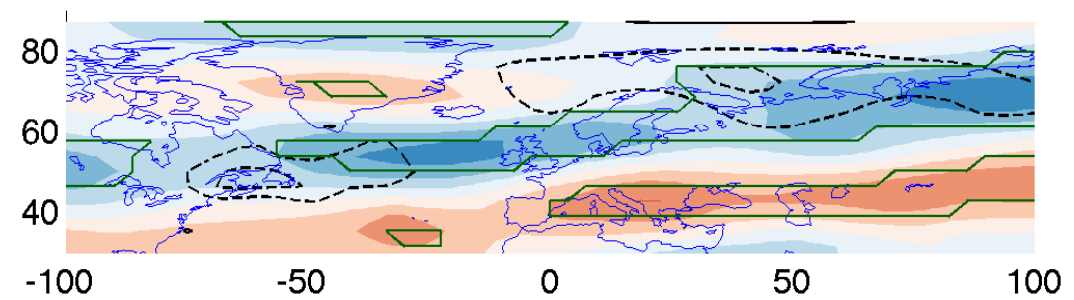

c) PRT-CTL U300 and v'T', days 41-60
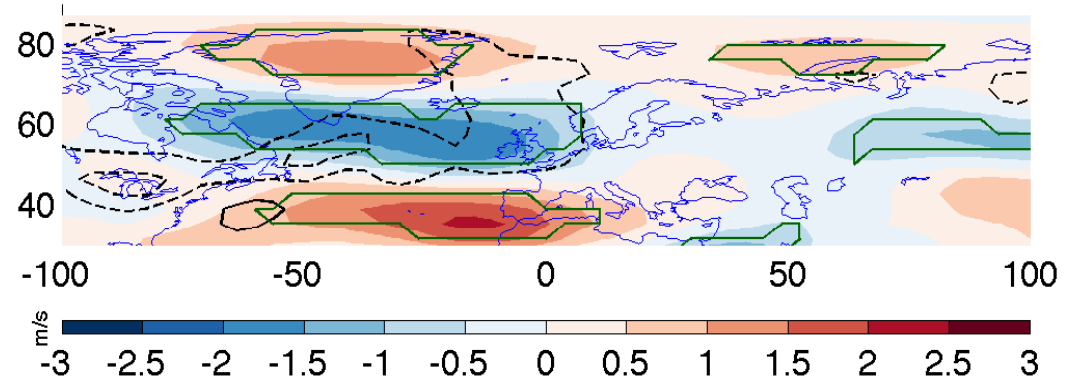

Figure 5. Projections of $U$ at $300 \mathrm{hPa}$ (shading, $\mathrm{m} / \mathrm{s}$ ) and transient eddy heat flux

$850 \mathrm{hPa}$ (contours, Km/s, drawn every 1), for a) day $1-20$, b) day 21-30, c)

ay 41-60. Fields are differences between PRT and CTL. The green solid line ncompasses statistically significant values at $99 \%$ confidence level according to a rạksum Wilcoxon test.

This article is protected by copyright. All rights reserved. 
a) SPEEDY $Z^{\star}{ }_{c}$ and $T^{\star}{ }_{p}{ }^{-}{ }^{*}{ }_{c}$ days $10-50$
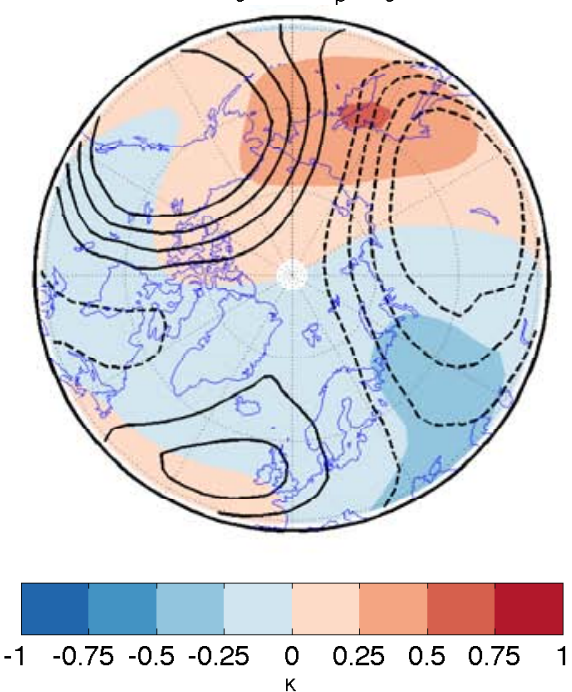

b) ERA Interim, $Z^{\star}{ }_{\text {clim }}$ and $T^{\star}{ }_{\text {anom }}$ JAN-FEB
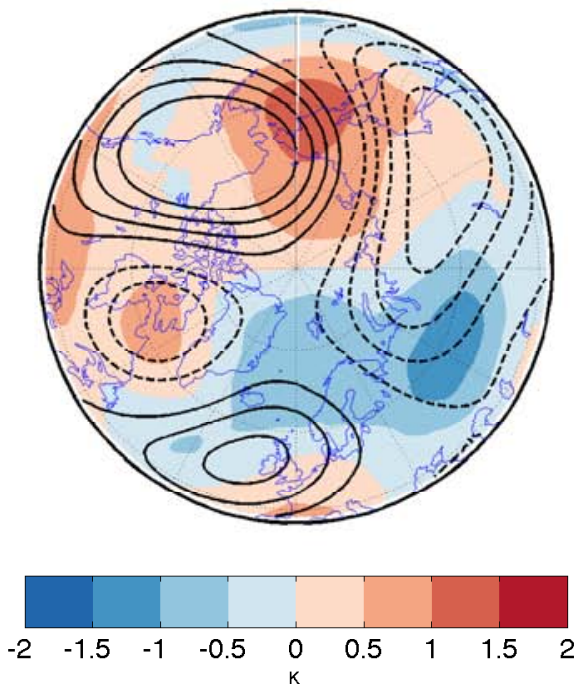

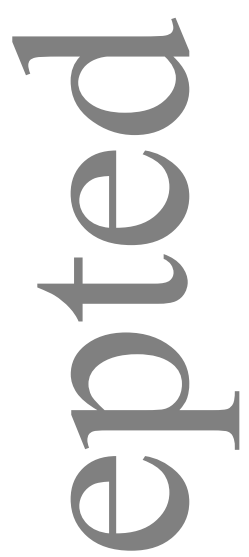

P

Figure 7. Projection of $T_{a}^{*}$ (shading) and $\bar{Z}_{c}^{*}$ (contours, drawn every $50 \mathrm{~m}$ ), at 100 $\mathrm{hPa}$ for a) PRT minus CTL averaged over days 15-50 and b) ERA Interim low DJF
. sea-ice anomaly in January and February.

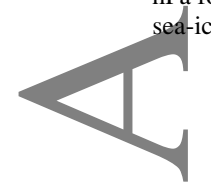

This article is protected by copyright. All rights reserved. 
a) Lagged regression of Z300, Z30 and $v^{*} T^{*}$ (PRT-CTL)

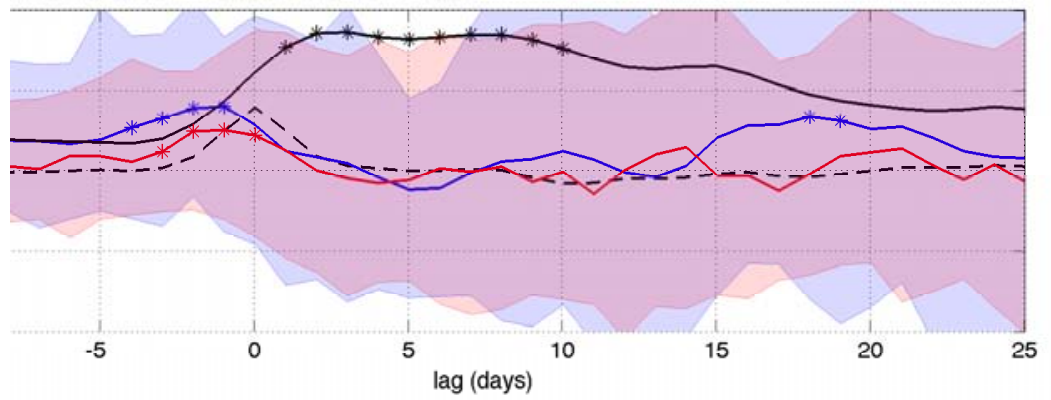

b) $Z 300$, lag $=-5 / 0$

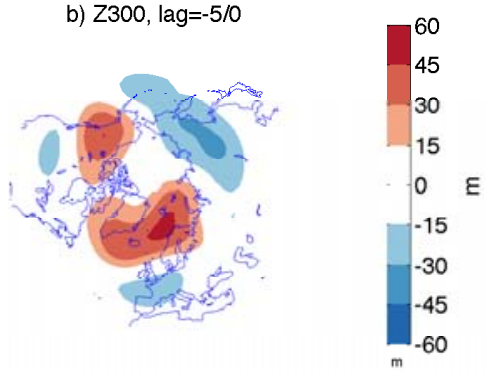

c) $Z 300$, lag $=17 / 22$

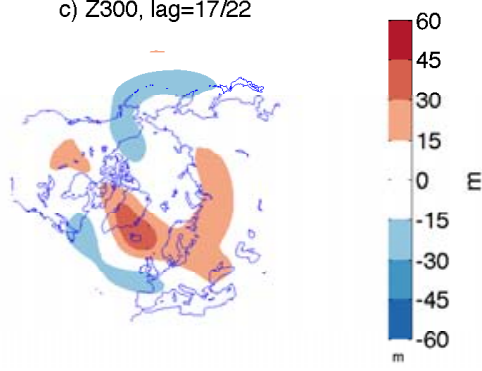

Figure 8. a) Lagged regression of geopotential height difference at $300 \mathrm{hPa}$ (PRT minus CTL) on the $100 \mathrm{hPa}$ eddy heat flux difference (lag-0) averaged zonally (black line), over the North Atlantic $(65 \mathrm{~N}-85 \mathrm{~N}, 60 \mathrm{~W}-0 \mathrm{~W}$, blue line) and over the sector $70 \mathrm{~N}-85 \mathrm{~N}, 30 \mathrm{E}-90 \mathrm{E}$ (B-K and Scandinavia, red line). Shadings indicate the interquartile range of the distributions. b) Stereographic projection of geopotential height anomaly (shading, PRT minus CTL) at $300 \mathrm{hPa}$ averaged between lag -5 and lag 0 and c) between lag 17 and lag 22.

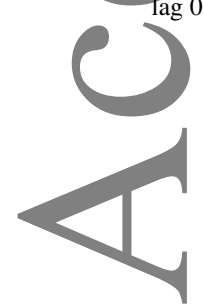

This article is protected by copyright. All rights reserved. 


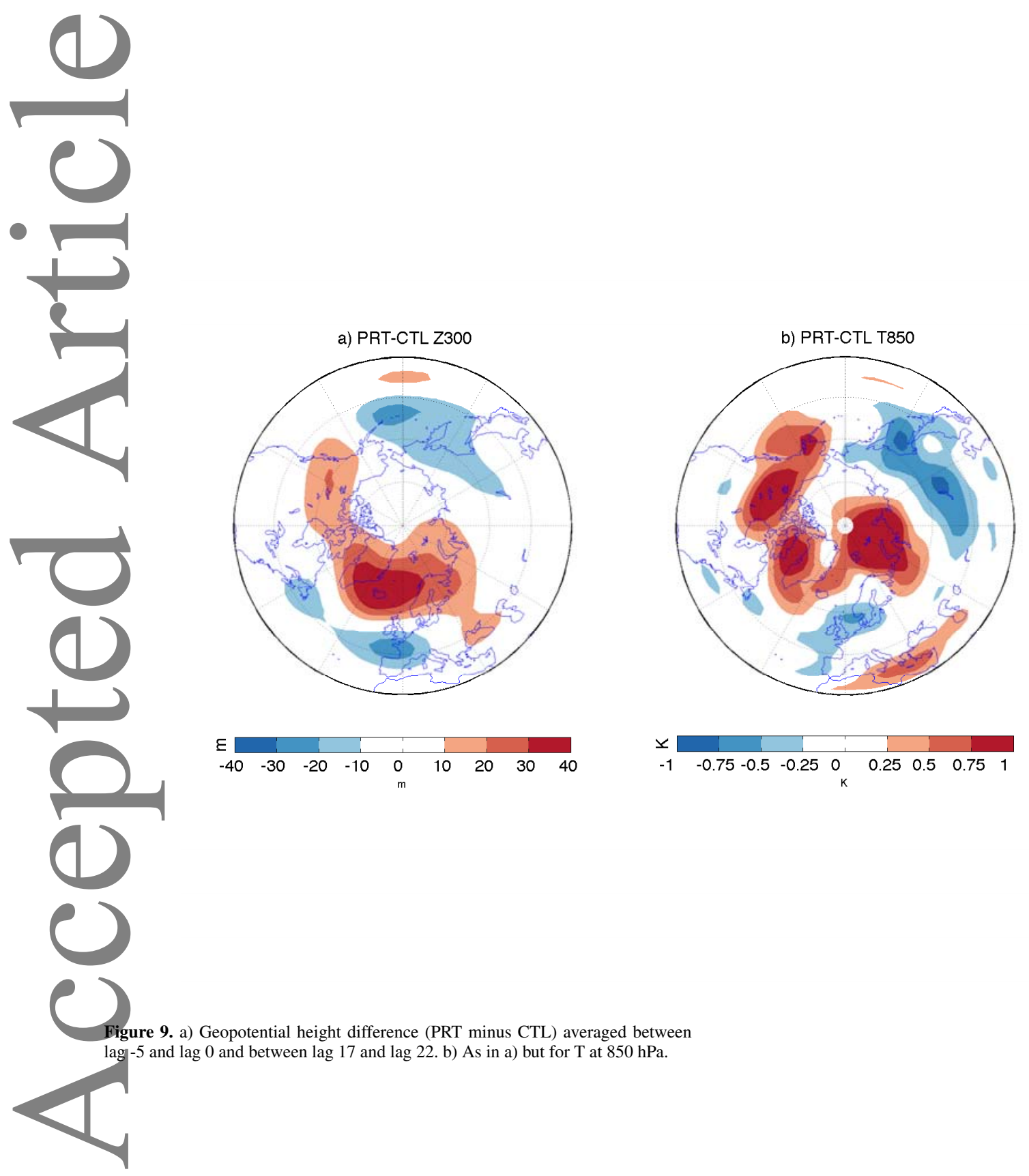

This article is protected by copyright. All rights reserved. 